Jurnal ABDINUS : Jurnal Pengabdian Nusantara, 2 (2), 2019, 122-128

Available online at: http://ojs.unpkediri.ac.id/index.php/PPM

DOI: https://doi.org/10.29407/ja.v2i2.12531

\title{
Penerapan Kesehatan Keselamatan Kerja (K3) Di UMKM Laundry Balikpapan
}

\author{
Yogiana Mulyani ${ }^{1}$, Praseptia Gardiarini ${ }^{1}$, Syahrul Karim ${ }^{1}$ \\ 1yogiana.mulyani@poltekba.ac.id, tiagardiarini@gmail.com, karim@poltekba.ac.id \\ ${ }^{1}$ Divisi Kamar \\ ${ }^{1}$ Politeknik Negeri Balikpapan
}

Received: 0910 2018. Revised: 2812 2018. Accepted: 11012019

\begin{abstract}
Laundry business is a business that currently developing in Balikpapan. Laundry is a necessity for Balikpapan residents who have a tight schedule so they don't have more time to wash. Balikpapan Laundry Community (KLB) is a community that was established to be a place for laundry entrepreneurs in Balikpapan. One of the problems encountered in KLB is the lack of understanding of the importance of paying attention to safety, job security (K3) in carrying out daily work. After finding the problem, it was determined the date of the implementation of K3 implementation training at the laundry work place which was held on 1 August 2018 at the Novotel Balikpapan Hotel. The implementation of the training includes the provision of material, filling out the pre and post test questionnaires, as well as the direct practice of the implementation of K3 in Laundry at Novotel Balikapan Hotel. There were 22 participants who were workers and laundry business owners who joined KLB. Based on the prepost test provided, participants' knowledge increased and after carrying out K3 training at the Balikpapan Laundry Unit, participants became more aware of K3 implementation at their respective businesses respectively. The conclusion obtained from this activity that every owner and worker in the laundry business must understand the OSH standards that must be provided at the workplace to ensure the health and safety of the work of everyone in the area.
\end{abstract}

Keywords: Laundry, Occupational Safety and Health

Abstrak: Usaha laundry merupakan suatu usaha yang saat ini mulai berkembang di Balikpapan. Laundry menjadi kebutuhan bagi warga Balikpapan yang memiliki jadwal padat sehingga tidak punya waktu lebih untuk mencuci. Komunitas Laundry Balikpapan (KLB) merupakan suatu komunitas yang didirikan untuk menjadi wadah bagi pengusaha-pengusaha laundry di Balikpapan. Salah satu permasalahan yang ditemui di KLB adalah kurangnya pemahaman tentang pentingnya memperhatikan keselamatan, keamanan kerja (K3) dalam melaksanakan pekerjaan seharihari. Setelah menemukan masalah tersebut dilakukan penentuan tanggal pelaksanaan pelatihan penerapan $\mathrm{K} 3$ di tempat kerja laundry yang dilaksakan pada tanggal 1 Agustus 2018 di Hotel Novotel Balikpapan. Pelaksanaan pelatihan meliputi pemberian materi, pengisian kuesioner pre dan post test, serta praktek langsung pelaksanaan K3 di Laundry di Hotel Novotel Balikapan. Peserta berjumlah 22 orang yang merupakan pekerja 
dan pemilik usaha laundry yang tergabung dalam KLB. Berdasarkan prepost test yang diberikan, pengetahuan peserta meningkat dan setelah melaksanakan pelatihan K3 di Unit Laundry Novotel Balikpapan, peserta semakin paham mengenai pelaksanan $\mathrm{K} 3$ di tempat usaha mereka masingmasing. Kesimpulan yang diperoleh dari kegiatan ini adalah bahwa setiap pemilik maupun pekerja di tempat usaha laundry harus memahami standar K3 yang harus disediakan di tempat kerja guna menjamin kesehatan dan keselamatan kerja setiap orang yang ada di wilayah tersebut.

Kata kunci: Laundry, Kesehatan Keselamatan Kerja

\section{ANALISIS SITUASI}

Usaha laundry merupakan suatu usaha yang saat ini mulai berkembang di Balikpapan. Laundry menjadi kebutuhan bagi warga Balikpapan yang memiliki jadwal padat sehingga tidak punya waktu lebih untuk mencuci. Prospek bisnis yang menjanjikan keuntungan banyak dengan modal sedikit ini menjadikan semakin banyak penyedia-penyedia layanan laundry. Namun sangat disayangkan masih banyak pengusaha-pengusaha laundry yang tidak memperhatikan keselamatan kerja para karyawan sehingga kecelakaan kerja tidak dapat dihindarkan. Macam kecelakan kerja yang pernah dialami oleh pekerja laundry antara lain : terhirup detergen dan pewangi yang berbahan dasar kimia dengan aroma yang menyengat, terluka saat menandai pakaian, terkena setrika saat merapikan pakaian dan terpeleset saat pencucian.

Komunitas Laundry Balikpapan (KLB) merupakan suatu komunitas yang didirikan untuk menjadi wadah bagi pengusaha-pengusaha laundry di Balikpapan. Komunitas ini baru saja didirikan tahun 2017. Beberapa kegiatan yang telah dilakukan adalah mengadakan workshop mengenai cara setrika yang berkualitas. Pengikut komunitas ini tidak hanya berasal dari Balikpapan saja namun dari berbagai macam daerah seperti Samarinda, Kutai, Paser, Bulungan hingga Berau. Salah satu permasalahan yang ditemui di KLB adalah kurangnya pemahaman tentang pentingnya memperhatikan keselamatan, keamanan kerja (K3) dalam melaksanakan pekerjaan sehari-hari. Banyak dari pekerja laundry yang tidak menggunakan alat pelindung diri saat melakukan kerja, namun kecelakaan kerja yang dirasa tidak berefek justru terjadi secara berulang dan mengakibatkan turunnya performance pekerja.

\section{SOLUSI DAN TARGET}

Adapun solusi yang ditawarkan yang pertama adalah penyuluhan tentang pentingnya menerapkan keselamatan kerja saat melakukan aktifitas pekerjaan. Kesehatan dan 
keselamatan kerja merupakan upaya perlindungan yang ditujukan untuk menjamin keselamatan tenaga kerja dalam melaksanakan tugasnya serta melindungi keselamatan setiap orang yang berada di tempat kerja tersebut dan melindungi keamanan peralatan dan sumber produksi agar selalu dapat digunakan secara efisien (Suma'mur, 2009). Secara filosofis dan teknis kesehatan dan keselamatan kerja merupakan cara berpikir dan upaya nyata untuk menjamin keberlangsungan tenaga kerja pada khususnya dan masyarakat pada umumnya (Utama, 2001).

Tujuan menerapkan kesehatan dan keselamatan kerja adalah menjamin rasa aman dan nyaman bagi karyawan dalam berkarya pada tiap pekerjaan, menciptakan masyarkat dan lingkungan yang sehat dan sejahtera serta bebas dari kecelakaan dan penyakit akibat kerja dan berpartisipasi melaksanakan pembangunan nasional dengan prinsip pembangunan berwawasan lingkungan.

Solusi kedua yaitu sosialisasi penggunaan rambu-rambu atau tanda peringatan mengenai K3. Rambu-rambu K3 yaitu alat bantu yang berfungsi untuk menginformasikan bahaya dan untuk melindungi kesehatan serta keselamatan pekerja yang berada di wilayah kerja, jika dijabarkan maka fungsinya antara lain: (Erizal, 2018) Menarik perhatian setiap orang akan adanya tanda bahaya, menunjukkan kemungkinan adanya potensi bahaya yang tidak terlihat di wilayah kerja, menyediakan informasi secara umum serta memberikan pengarahan, menginformasikan kepada pekerja tentang waktu kapan harus menggunakan alat pelindung diri, menginformasikan letak perlatan darurat untuk menyelamatkan diri saat terjadinya bahaya dan memberikan peringatan waspada terhadap tindakan atau perliku yang tidak dibolehkan saat bekerja.

\section{METODE PELAKSANAAN}

Survei dilaksanakan bulan Maret 2018 di beberapa tempat laundry yang tergabung dalam Komunitas Laundry Balikpapan. Survei dilakukan di tiga tempat laundry dan mendapatkan masalah terkait penerapan K3 yang perlu menjadi perhatian dan peningkatan diantaranya: belum menyadari pentingnya menerapkan $\mathrm{K} 3$ di tempat kerja, belum tersedianya alat pelindung diri di beberapa tempat usaha laundry dan belum diadakannya P3K.

Setelah menemukan masalah tersebut dilakukan penentuan tanggal pelaksanaan pelatihan penerapan K3 di tempat kerja laundry yang dilaksanakan pada tanggal 1 Agustus 2018. Di Hotel Novotel Balikpapan pelaksanaan berjalan lancar dan tertib, peserta yang hadir 
Jurnal ABDINUS : Jurnal Pengabdian Nusantara, 2 (2), 2019, 122-128

Yogiana Mulyani, Praseptia Gardiarini, Syahrul Karim

pertama-tama diberikan pre test untuk mengukur seberapa besar pengetahuan tentang $\mathrm{K} 3$ dan kemudian diberikan materi serta kunjungan langsung ke bagian laundry Hotel Novotel Balikpapan.

\section{HASIL DAN LUARAN}

Hasil kegiatan sosialisasi pengabdian kepada masyarakat pada tanggal 1 Agustus 2018 dihadiri oleh Komunitas Laundry Balikpapan yang berjumlah 22 orang. Peserta yang hadir dalam pengabdian masyarakat tersebut adalah pekerja dan pemilik dari Usaha Laundry yang tergabung dalam UMKM Laundry Balikpapan.

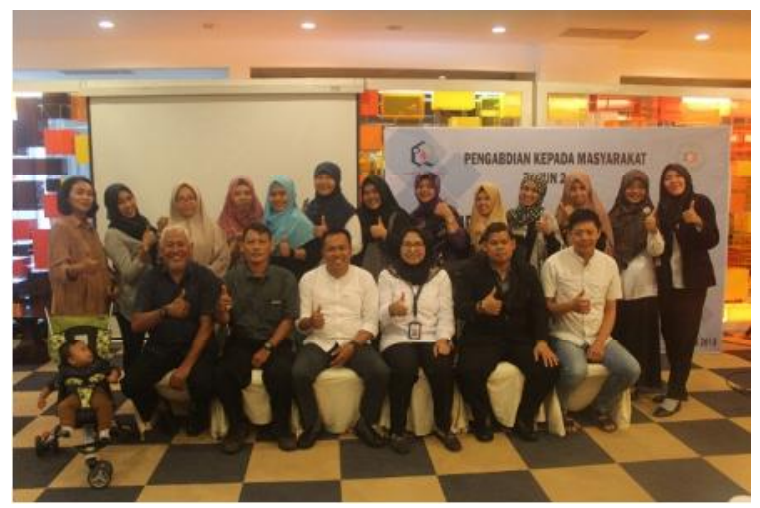

Gambar 1. Peserta dan Pelaksanaan Pengabdian Masyarakat Prodi Divisi Kamar tahun 2018

Adapun hasil kegiatan sebagai berikut.

1. Sosialisasi Pengetahuan tentang Pelaksanaan K3 di tempat kerja laundry

Sosialisasi dilaksanakan pada tanggal 1 Agustus 2018 bertempat di Hotel Novotel Balikpapan. Kegiatan berlangsung dengan lancar dan tertib. Peserta terlihat sngat antusias dalam mengikuti sosialisasi yang diberikan. Sosialisasi yang diberikan berupa pemaparan tentang pentingnya memperhatikan aspek K3 dalam menjalankan usaha laundry. Tema yang diberikan adalah "Penerapan K3 di UMKM Laundry Balikpapan”.
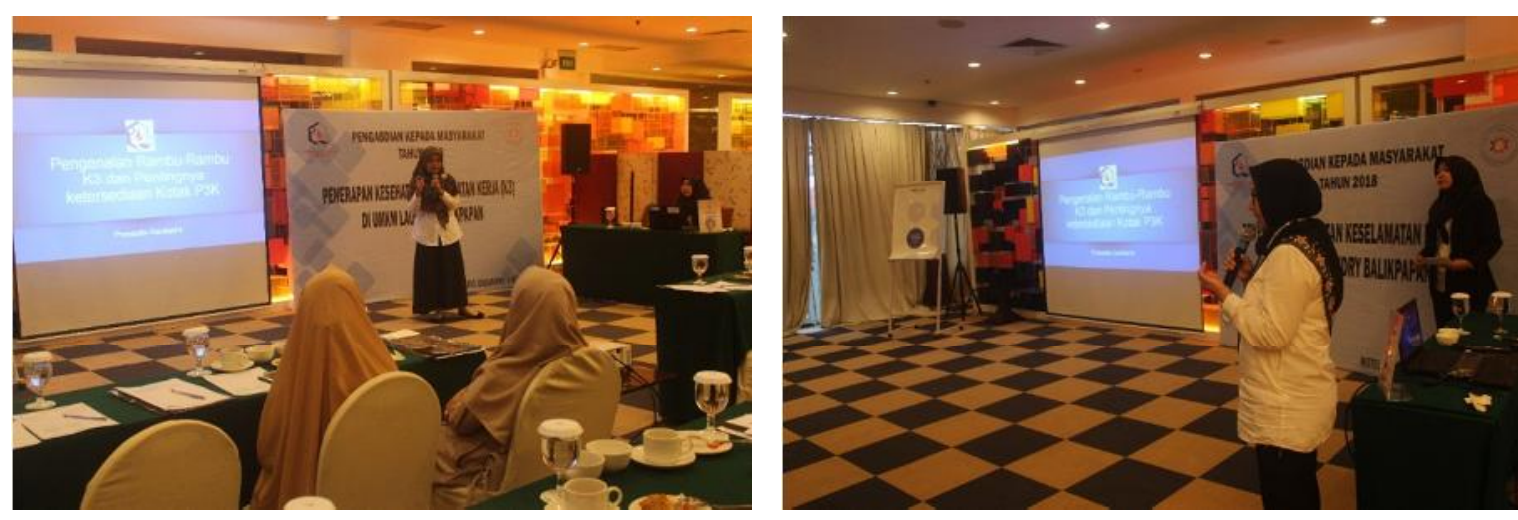

Gambar 2 dan 3. Pemberian Sosialisasi Pengetahuan tentang Pelaksanaan K3 di tempat kerja laundry 
Jurnal ABDINUS : Jurnal Pengabdian Nusantara, 2 (2), 2019, 122-128

Yogiana Mulyani, Praseptia Gardiarini, Syahrul Karim

Pemberian sosialisasi tersebut bertujuan agar setiap usaha Laundry di Balikpapan mampu mengaplikasikan pengetahuan yang telah didapatkan dengan wujud menyediakan serta mendukung adanya upaya K3 di tempat kerja.

2. Pelatihan K3 di Laundry Hotel Novotel Balikpapan

Selain pemberian materi tentang penerapan K3 di tempat kerja Laundry, peserta juga diajak untuk melihat langsung penerapan K3 yang telah dilakukan oleh manajemen laundry hotel Novotel Balikpapan.

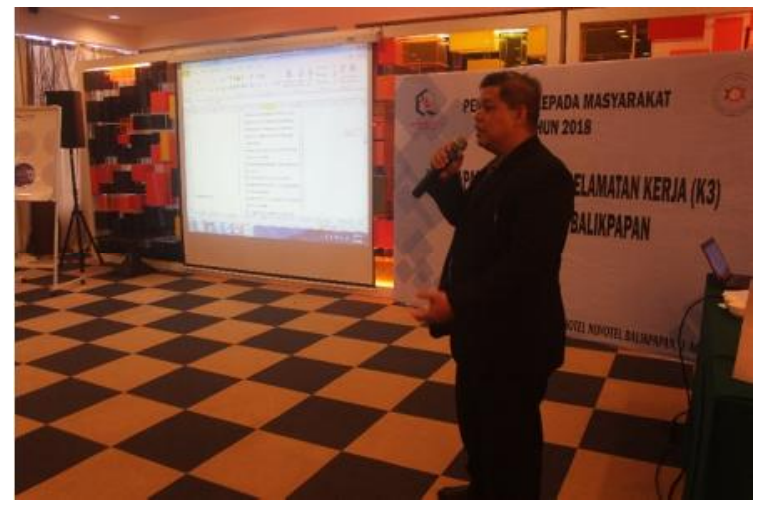

Gambar 4. Pemberian Materi Pelaksanaan K3 di tempat kerja laundry

Peserta dapat mengamati secara langsung bagaimana pegawai Laundry Novotel telah melakukan penerapan K3 dalam menyelenggarakan usaha Laundry dilihat dari adanya Rambu-Rambu K3, ketersediaan kotak P3K dan penggunaan alat pelindung diri oleh karyawan.
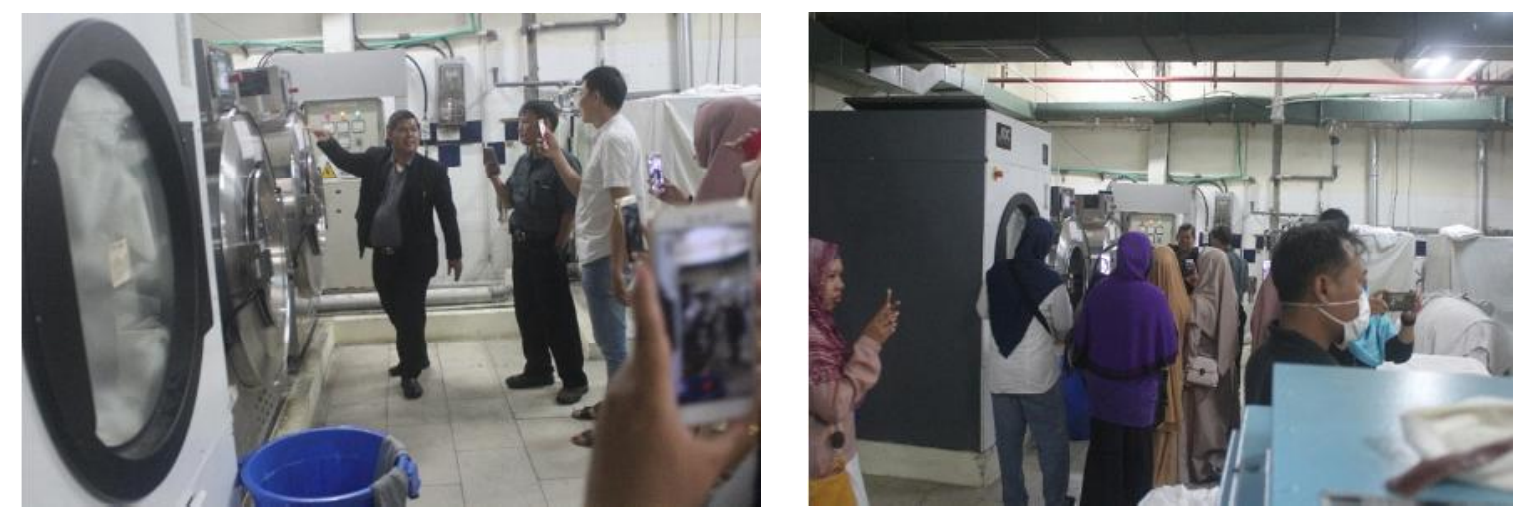

Gambar 5 dan 6. Pelatihan K3 di Laundry Hotel Novotel Balikpapan

3. Pemberian Pre Test dan Post Test

Pemberian pre test diberikan sebelum peserta menerima materi yang disampaikan mengenai penerapan K3. Peserta mengerjakan soal sejumlah 15 butir soal pilihan ganda yang ditujukan untuk mengetahui seberapa besar pengetahuan peserta terhadap komponen $\mathrm{K} 3$. 

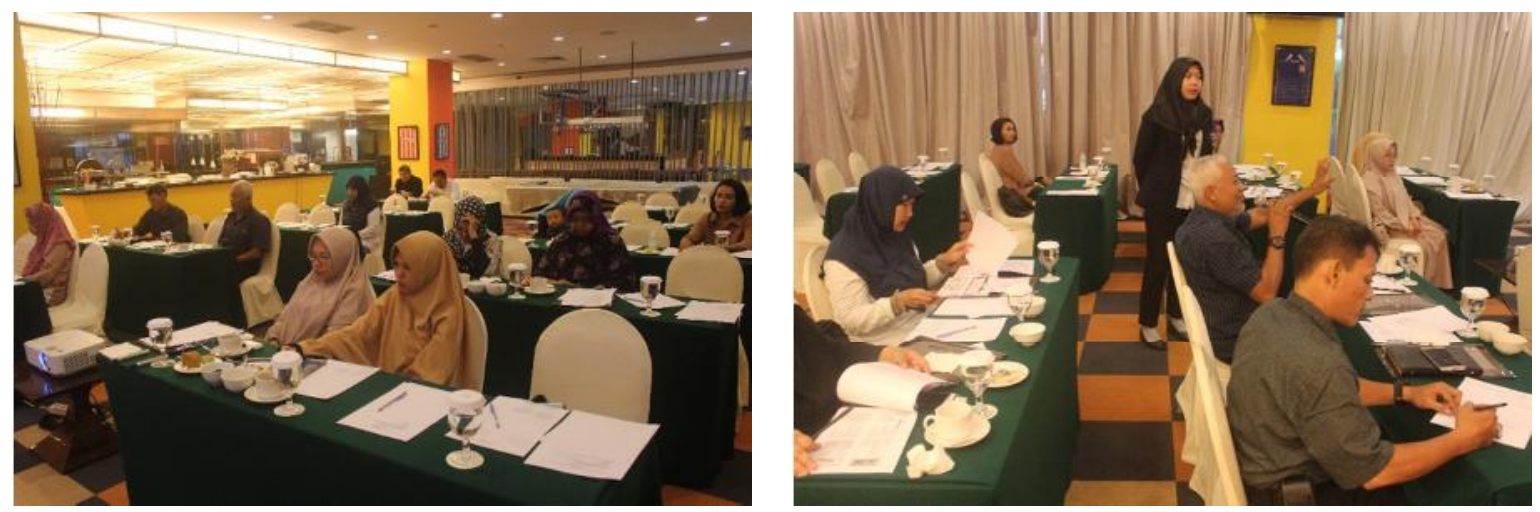

Gambar 7 dan 8. Pemberian Pre Test dan Post Test

Setelah diberikan materi sosialisasi mengenai penerapan K3, peserta kembali diberikan soal yang sama untuk melihat seberapa besar tingkat penambahan pengetahuan yang telah diperoleh masing-masing peserta. Setelah dilakukan pengecekan terhadap pre test dan post test didapakan bahwa pengetahuan seluruh peserta mengalami peningkatan sebesar $100 \%$.

\section{SIMPULAN}

Pelaksanaan program pengabdian kepada masyarakat dengan judul "Penerapan Kesehatan Keselamatan Kerja (K3) Di UMKM Laundry Balikpapan” dapat disimpulkan bahwa yang pertama program pengabdian masyarakat ini memberikan perubahan pengetahuan dan perilaku para pengusaha laundry yang tergabung dalam Komunitas Laundry Balikpapan dalam menerapkan K3 dalam menjalankan usaha laundry. Kedua bahwa salah satu rangkaian pelatihan yaitu melakukan pengecekan terhadap pemasangan alat-alat atau rambu-rambu K3 di tempat kerja laundry Novotel yang dijadikan contoh untuk diterapkan di tempat kerja maisng-masing unit usaha. Terakhir bahwa secara keseluruhan kegiatan pengabdian masyarakat dari perguruan tinggi sangat diharapkan oleh masyarakat dalam mengimplementasikan ilmu dan hasil penelitian ditengah-tengah masyarakat.

\section{DAFTAR RUJUKAN}

Ardiansyah, M. (2015). PENGETAHUAN KARYAWAN AKAN PENTINGNYA PENGGUNAAN ALAT PELINDUNG DIRI (APD) DALAM UPAYA MENJAGA KESEHATAN DAN KESELAMATAN KERJA (Studi pada PT. Iskandar Indah Printing Textile Surakarta Bagian Weaving). Solo: Universitas Muhamadiyah Surakarta.

Erizal. (2018, April 23). web.ipb.ac.id. Retrieved from web.ipb.ac.id: web.ipb.ac.id/ erizal/manpro/menerapkan_k3.pdf 
Jurnal ABDINUS : Jurnal Pengabdian Nusantara, 2 (2), 2019, 122-128

Yogiana Mulyani, Praseptia Gardiarini, Syahrul Karim

PERMEN, MEN/VII/2008.

PERMEN, PER/01/MEN/1981 (Indonesia 1981).

Suma'mur. (2009). Higene Perusahaan dan Kesehatan Kerja (HIPERKES). Jakarta: Sagung Seto.

Utama, W. W. (2001). Manajemen Sumber Daya Manusia. Denpasar: UPT Udayana. 